Journal of Economics and Behavioral Studies

Vol. 5, No. 1, pp. 8-17, Jan 2013 (ISSN: 2220-6140)

\title{
Internal Mainstreaming of HIV and AIDS in Zimbabwe's Non-Governmental Organisations
}

\author{
Rutendo Fran Chitapi ${ }^{1}$, ${ }^{*}$ Togara Warinda ${ }^{2}$ \\ ${ }^{1}$ Plan International Zimbabwe, Zimbabwe \\ ${ }^{2}$ University of Zimbabwe, Zimbabwe \\ *twarinda@commerce.uz.ac.zw
}

\begin{abstract}
Organisations remain exposed to risk and are vulnerable to HIV and AIDS impacts for as long as they are unprepared to mainstream HIV and AIDS. Certainly without infusing sustainable strategies for the HIV and AIDS pandemic into day to day operations there would be considerable waste of resources. This study sought to establish the level of internal mainstreaming of HIV and AIDS in an international NGO operating in Zimbabwe. Questionnaires were used to collect data from a sample of employees of the NGO, while senior managers were interviewed. Relevant internal documents were also reviewed to help ascertain the extent of internal mainstreaming in the NGO. The main finding was that HIV and AIDS internal mainstreaming had not been successfully done. While the organisation had certain comparative advantages, these were not harnessed to address the causes and effects of HIV and AIDS in an effective and sustained manner within the NGO. The major barrier was lack of commitment by senior management of the NGO. While management were aware of the impacts of HIV and AIDS, there were no tools to enable them to quantify the effect on the NGO. Getting it right for this NGO does not require more financial resources but a paradigm shift and modifying or realigning what is already on the ground for an effective and sustained response to HIV and AIDS.
\end{abstract}

Keywords: internal mainstreaming, HIV and AIDS, barriers, prevalence

\section{Introduction}

Sub-Sahara Africa is heavily affected by the Human Immunodeficiency Virus (HIV) and the Acquired Immune Deficiency Syndrome (AIDS) more than any other region of the world (UNGASS, 2010). An estimate of 22 million people were living with HIV at the end of 2007 and approximately 1.9 million additional people were infected with HIV during that year while by 2008, the AIDS pandemic in Africa had claimed the lives of an estimated 1.5 million people in the region, leaving more than 11 million children orphaned by AIDS (UNAIDS 2008). HIV/AIDS has had a debilitating effect on the labour force. Absenteeism is one such effect. According to Bill (2005) HIV positive employees at a South African sugar company took a total of 55 days off sick as leave in the last 2 years of their lives. Absenteeism includes absence of infected persons and caregivers from work as well as absences to attend funerals of co-workers and relatives. According to UNAIDS (2003) estimates, the cost of absenteeism in East Africa stood at 25-54\% of employment costs. HIV/AIDS has become a critical challenge for companies in Southern Africa, where, according to Professor Diana Barret of the Harvard Business School (2003), 90\% of their workers attend 3 funerals per week. HIV/AIDS also results in untimely retirement due to ill health; employee deaths and hiring of ad-hoc staff to fill the gap due to absenteeism. The epidemic is most prevalent among the 15-49 years age group which comprises a large number of the workforce. Pennap, et al (2011), posit that capital growth in sub-Saharan Africa fell by $0.5-1.2 \%$ as a direct result of HIV/AIDS. Productivity patterns have changed enormously with disastrous economic implications to organisations. With HIV/AIDS, come increased costs associated with recruitment, staff training to replace and retain the required number of employees, lost skills and morale, death benefits, medical assistance, and increased use of unskilled manpower.

In Zambia, for example, ING Barings Bank (2004) reported that between 1994 and 2002, 62 percent of deaths among managers were the result of AIDS-related illnesses. This rate was slightly higher than middle-level workers and slightly lower than lower-level workers. A survey of blood donors in Malawi found higher infection levels among the educated than unskilled workers. According to International Labour Organisation 
(2000), a pilot study of enterprises in South Africa established that fewer than 40 percent of employers believed they had a good chance of replacing skilled workers. Also in South Africa, the ING Barings Bank projected that one-third of the semi-skilled and unskilled workforce would be HIV-positive by 2005; 23 percent of the skilled and 13 percent of the highly skilled workforce. The International Labour Organisation (ILO) estimates that over two thirds of those living with HIV and AIDS go to work (ILO Global estimates, 2006). Therefore, tackling the impact of HIV and AIDS on productivity of the workforce and enterprise efficiency in all sectors of economic activity and development should be a major concern. Interventions by both government and the international community and local players have yielded positive results. However, the Non Governmental Organisations (NGOs) sector remains vulnerable to HIV and AIDS despite the recorded positive trends. James, et al. (2006) in their pilot study on the cost of HIV/AIDS to NGOs, estimated that average staff costs increased by $12.5 \%$ due to HIV/AIDS. The same study found that programme impact of NGOs were perceived to drop by more than $20 \%$, while output went down by about $12.4 \%$. Employees of NGOs are highly susceptible to HIV/AIDS partly due to the nature of their work. Most of these are field workers who have to be out where actual activity is taking place, away from their families and spouses. In Zimbabwe, NGOs are slowly waking up, like many international businesses before them, to the fact that HIV and AIDS are threatening their performance and effectiveness. In Zimbabwe, HIV and AIDS are not only infecting and affecting a significant proportion of NGOs' beneficiary groups, but are also having an impact on their own organisations. NGOs struggle due to loss of staff through sickness, death, and care for relatives, funerals, reduced performance of staff because of sickness or distraction; and rising medical expenditures. This results in declining output and increasing overhead costs. In recent years many organisations have therefore started to manage HIV and AIDS in their own workplaces through HIV workplace policies and programmes, also referred to as internal mainstreaming.

At this point it is worth looking at the HIV and AIDS picture in Zimbabwe which informs the NGOs sector, thus putting the larger picture into perspective. Zimbabwe is amongst countries with the highest HIV prevalence in the world. Although the overall HIV prevalence in the adult population has been steadily decreasing from an estimated $24.6 \%$ in 2004 to an estimated $15.6 \%$ in 2007 and declining further to $13.7 \%$ in 2008 (Ministry of Health and Child Welfare 2009). UNAIDS (2010) paints a somewhat different scenario, estimating that the HIV/AIDS prevalence rate for the 15-49 years age group at $14.3 \%(23.7 \%, 2001)$. The same report put the estimates of new infections on the same age group at $0.84 \%$ (2009) against $1.94 \%$ in 2001.The HIV and AIDS pandemic continues to pose a severe development challenge. According to the Ministry of Health and Child Welfare, the decline in HIV prevalence is indicative of a change in sexual behavioural pattern. However, life expectancy fell from 50 years in 1995 to 34 years in 2007 (UNAIDS 2008) due to the impact of AIDS on the population. Within the 15-49 years age group lays the most productive labour force of any given country. The figures above suggest that in Zimbabwe that is the group with the highest prevalence. Thus it can be said that HIV/AIDS is playing havoc on the most productive age group. The rate at which the country's workforce is being depopulated by the disease is alarming. Most workplaces in Zimbabwe are now characterised by high staff turnover, frightening loss of critical skills and specialist knowledge, millions of lost man-hours and an accelerated reduction in productivity because of the impact of HIV and AIDS on employees. It takes time to replace the skilled workers because of the training or re-training necessary, and even longer to replace the experience lost as key workers are affected. NGOs in Zimbabwe and elsewhere have and continue to play a leading role in mitigating the effects of HIV and AIDS in the communities they operate. Despite this they are not sacrosanct and are equally affected by the pandemic like the general populace in which they operate. Where for instance there is massive loss of man-hours, loss of skills, high staff turnover in the country etc. the same can be said of NGOs operating in that particular country. If NGOs are seen as part of the army to combat the pandemic it is important that they also apply interventions within themselves to reduce or mitigate HIV and AIDS impacts. It is in light of this that this study sought to assess the success (or lack of it) of HIV and AIDS internal mainstreaming in one NGO operating in Zimbabwe.

\section{Literature Review}

HIV refers to the Human Immunodeficiency Virus and AIDS refers to the Acquired Immune Deficiency Syndrome. The virus attacks and weakens the body's immune system eventually resulting in death of the infected. Most of the people that are infected with or affected by HIV and AIDS are young and/or middle- aged 
adults who want and/or need to carry on working. These people may find it difficult to stay at work, sometimes because of illness or because they are being discriminated by fellow employees and managers. This raises many legal issues, most of which are governed by the labour laws and constitutional laws in most countries (UNAIDS 2002). Concerted effort has been and continues to be made to combat HIV and AIDS through various interventions. There has been a gradual shift from strictly bio-medical interventions to the HIV/AIDS pandemic towards integrated approaches which seek to treat HIV/AIDS as a development issue. Over the last few years, there has been increasing talk within governments, multi- and bilateral organisations, and development organisations of "mainstreaming AIDS" into all sectors, and of "taking a multi-sectoral approach to AIDS." This has seldom been accompanied by practical guidance on what a "multi-sectoral approach' entails, or what an organisation that 'mainstreams AIDS' might look like (Mullins, 2002). Governments and donors are increasingly talking about HIV and AIDS mainstreaming, but few give a clear definition of what they mean by the term. To further confuse matters, the term mainstreaming is often used interchangeably with terms such as 'the multi-sectoral response' or 'integrating HIV and AIDS' (Holden 2003). According to the HIV and AIDS Mainstreaming Working Group (2002), mainstreaming HIV and AIDS can be defined as "the process of analysing how HIV and AIDS impacts on all sectors now and in the future, both internally and externally, to determine how each sector should respond based on its comparative advantage." Mainstreaming is distinct from integration in that, integration "occurs when HIV and AIDS issues and interventions are introduced into a project, programme or policy context as a broad component or content area without much regard for the specific core business of an institution or the main purpose of development" (UNAIDS and GTZ, 2002:5). Mainstreaming on the other hand integrates and aligns HIV/AIDS as a discrete set of activities in a holistic approach while focussing on the core mandate of the organisation (UNAIDS and GTZ, 2002).

HIV/AIDS mainstreaming can be viewed from two perspectives: the internal and the external domains. Internal mainstreaming entails adapting organisational policies and practices in order to reduce its susceptibility and vulnerability to HIV/AIDS infections and impacts (VSO, 2004). An organisation should implement measures to reduce the likelihood of employees getting infected and to reduce its vulnerability to HIV/AIDS impacts. Internal systems and procedures have to be re-examined and adapted accordingly to reduce the negative impacts of HIV/AIDS on the organisation (Department of Provincial Local Government (DPLG), 2007). Employees have to be educated to increase their awareness of HIV/AIDS. Where possible organisations should provide or facilitate access to anti-retroviral therapy (ART) to employees. Human resource policies on recruitment and succession planning have to be realigned with for instance national laws and regulations on HIV/AIDS. Also within this context, ensuring that human resources planning, training and recruitment take into consideration future staff depletion rates, the disruption caused by increased morbidity and mortality. The overarching aim of internal mainstreaming is "...to try to ensure that the organisation can continue to operate effectively in the face of HIV/AIDS and continue to fulfil its mandated functions" (DPLG, 2007). Internal mainstreaming is considered as an 'entry gate' to external mainstreaming (Zambian Governance Foundation (ZGF), 2011). On the other hand the focus of external mainstreaming is assessing how an organisation's “... day to day work contributes to vulnerability to HIV infection and how their work impacts on people's ability to cope with HIV/AIDS" (Halogen, 2009). External mainstreaming requires all organisations in executing their mandate to ensure their core business is relevant to the societal dynamics brought about by HIV/AIDS. In the process an organisation's overall strategy may need modifications which will cascade to programme planning and implementation activities (Mullins, 2002). External mainstreaming takes cognisance of the fact that regardless of the work the organisation undertakes, its external stakeholders are at some point either infected or are affected by HIV/AIDS. Organisations have to be aware that their operations may become less relevant to, or accessible by affected and infected people (Mullins, 2002). According to UNAIDS (2004) any mainstreaming effort requires answers to the following questions:

- How do AIDS affect our organisation and our work both now and in the future?

- How may our work mitigate or aggravate susceptibility to HIV infection and vulnerability to the impacts of AIDS?

- Where does our comparative advantage lie in responding to those effects? 
The above questions provide a framework that organisations may use in both internal and external mainstreaming. Staff awareness needs to be raised in such a way to reduce their susceptibility to infection and enable them to cope should they become infected. Staff education can include basic information on HIV transmission, progression from HIV to AIDS; treatment; legal rights of people living with HIV and discrimination and can help enhance counselling skills. A second mechanism is to develop HIV and AIDS or Critical Illness/Health policies covering issues such as human resource management, welfare and insurance policies, availability of condoms, access to antiretroviral (ARV) treatment and sick leave and recruitment. Organisations need to devise long term strategies to mitigate the impact of HIV and AIDS. This may involve extra-staffing at certain levels or multi-skilling staff in order that people can cover for each other when necessary. The effects of HIV and AIDS and the implementation of policies to manage the impacts will inevitably raise costs for organisations; and organisations need to alter their budgets to take into account these extra costs, otherwise money will be re-directed from other budget lines or policies/programmes will not be implemented. With particular reference to internal mainstreaming 'The Sphere Project 2004' suggests three important factors to make it more effective. First, organisational systems should be appropriate for the development stage an organisation is in. Another factor is organisational culture with regard to openness to address HIV and AIDS. Finally conducting HIV and AIDS risk/impact assessment to identify the susceptibility and vulnerability of an organisations to HIV and AIDS, and its capacity to deal with internal mainstreaming. These factors imply that there is need to foster effective leadership on HIV/AIDS. This may mean developing key performance indicators for managers to assess performance against cross cutting issues and HIV/AIDS mainstreaming (Halogen, 2009).

Mainstreaming HIV/AIDS has not been without its challenges. UNAIDS, IATT (2008) summarised the challenges or barriers in what they refer to as the 8 Cs: Capacity; Culture; Commitment; Context; Coverage; Competition; Cost; and Collaboration. A critical feature of mainstreaming is to take account of an organisation's mission, mandate and comparative advantages and relate these to the direct and indirect aspects of the epidemic. Lack of commitment from senior leadership has often negatively affected mainstreaming efforts of organisations. It is senior management that harness and marshal organisational resources towards the attainment of organisational goals and hence their disinterest on HIV/AIDS mainstreaming is major drawback. Top managers are responsible for ensuring that the workplace is a fair and effective environment that fosters productivity and creativity. However, policies will have no effect if management and other leaders do not demonstrate through their own words and actions their attitudes about HIV and AIDS workplace policies. In some instances, organisations lack capacity coupled with poor conditions of service for employees which make mainstreaming an uphill task. According to UNAIDS report (2002) money can only be used efficiently if there are sufficient human resources available, but there is an acute shortage of trained personnel in many organisations to deal with HIV and AIDS workplace policies. Employees must be given the tools, resources, training and support necessary to respond appropriately to HIV and AIDS policies. Sheer lack of knowledge on HIV/AIDS as well as stigma and discrimination which impede access to HIV testing, prevention, treatment and care are often identified as barriers to mainstreaming. In some organisations the HIV/AIDS activities are assigned to a single person in addition to his or her other duties. Mainstreaming HIV and AIDS calls for a profound paradigm shift in the mind-sets of every employee in every company right from the chief executive officer (CEO) down to the lowest operative in the organisation hierarchy. In essence this leads to another argument; "How does mainstreaming HIV and AIDS relate to organisational culture?" Strategy formulation of any kind is a cultural activity (Bate, 2002). Bate argues that cultural change is strategic change and hence it is inconceivable to treat strategy and culture as separate entities that require two separate processes.

In view of Bate' $s$ argument mainstreaming HIV and AIDS issues into an organisation's strategic planning process automatically draws into the fore critical cultural issues. For instance where organisational culture changes wants to focus on HIV and AIDS as strategic business issues the evidence must be seen starting from the strategic planning level. At that level the issues should be clearly articulated in the mission statement, aims, and objectives before they are translated into policies, programmes and action plans. From Baker, et al. (2004) it can be noted that most interventions do not seek to address the issues of HIV and AIDS at the organisational strategic planning level. The only work that attempted something near this is a programme that was run in Thailand called 'Using Incentives to Encourage AIDS Programs \& Policies in the Workplace'. 
However this programme merely encouraged the top managers to increase workplace programmes and policies without addressing the issue of strategic planning. The main crux is that to have an HIV and AIDS programme in the workplace is one thing and yet to strategically have an HIV and AIDS programme in the workplace is another thing. According to Koster, et al. (2009), mainstreaming HIV and AIDS has a number of benefits to both staff and the organisation which include an increase in the AIDS knowledge, competence and awareness levels within an organisation. For example, employees know that their organisation has a workplace policy in place, and understand the importance of developing such a policy and how this is done. Also, employees are more aware of their rights, responsibilities and services available to them that come along with the HIV workplace policy. There is increased openness in the workplace and greater ability to talk about HIV and AIDS and how it affects staff personally and their organisation. Knowledge, understanding and awareness of staff of HIV/AIDS are improved thereby reducing stigma and discrimination. Internal mainstreaming increases the likelihood of achieving programme goals by limiting the impact of HIV/AIDS on the organisation (ZGF, 2011).

Reduction of stigma and discrimination in the workplace concerning HIV and AIDS in general and towards People Living with HIV and AIDS (PLWHAS) in particular is another benefit of mainstreaming (Mauambeta, 2008). This is achieved through the participatory process of developing the workplace policies; there is increased intention and willingness among staff to disclose their status within the workplace if they are HIV positive. Related to this, staff have felt more confident that they would not lose their job if found to be HIV positive. Organisations have increased interaction with HIV service providers, for example for promotion of Voluntary Counselling and Testing (VCT). This has increased access to these services for staff and lead to improved service seeking behaviour by staff. In particular, creating a safe environment has lead to more staff getting tested for HIV, and more staff on anti retroviral treatment (Chibukire, 2007). The objective of mainstreaming HIV and AIDS in the workplace is to enhance the ability of an organisation and its staff to anticipate, minimise and cope with illness and death associated with the pandemic. This entails the need to understand and balance the interests of the staff and of the organisation (ILO, 2006). Mullins (2002) says all organisations in all sectors need to take steps to ensure their core business is relevant to the changes in societies and families brought about by HIV and AIDS. This aspect of mainstreaming seeks to strengthen the organisation's core business, without changing the focus to health care. This may entail modifications to the organisation's overall strategy, and to its detailed programme planning and implementation. There has been much talk about mainstreaming HIV and AIDS issues within organisations but there is little or no practical evidence of mainstreaming these HIV and AIDS issues within the NGO sector. It is important to walk the talk. Staffs is not aware of their rights hence there is no breaking of the silence around HIV and AIDS issues, there is no information to make informed decisions and to access treatment, care and support. Issues of stigma are high in people living with HIV and AIDS. It is important for organisations to become aware of the costs of HIV and AIDS to proactively start addressing HIV and AIDS issues in the organization. In general, NGOs are concerned with mainstreaming HIV and AIDS issues in the communities where they operate and not in their own organisations.

It is against this background that the study sought to evaluate internal mainstreaming of HIV and AIDS within an NGO operating in Zimbabwe. The objectives of this research were therefore:

- To determine the challenges of internal mainstreaming HIV and AIDS in NGOs in Zimbabwe

- To assess the extent of internal mainstreaming of HIV and AIDS within the targeted NGO in Zimbabwe

- The major findings and discussions in this study proffer convincing answers to research questions stated below:

- What are the challenges of internal mainstreaming HIV and AIDS in not-for-profit organisations in Zimbabwe?

- What is the extent of internal mainstreaming of HIV and AIDS in the targeted NGO?

\section{The current study Subject background}

The study was based on the analysis of an international NGO in Zimbabwe, which has seven programme units in Kwekwe, Bulawayo, Mutoko, Chipinge, Chiredzi, Mutare, Mutasa and the head office in Harare. The 
Zimbabwe operations started in 1986 and at the time of the study the staff complement stood at 200, and the majority were field staff. The NGO focuses on Health, Education, HIV and AIDS, Water and Sanitation and Food Security. The NGO like other organisations had not been spared of the debilitating effects of HIV and AIDS among its own employees. In its in-house magazine, the NGO acknowledged that the spread of HIV and AIDS among its employees had been driven by such factors as multiple concurrent sexual partnerships against a background of high levels of male uncircumcision, and gender inequality are responsible for the spread of HIV (Planet 2008).

Study sample: The staff complement of the NGO was 200 employees made up of 7 top management staff, 7 middle management staff and 186 other staff. The total sample size was 62 respondents and this sample was assumed to be large enough to make inferences on the population. The sample was $31 \%$ of the population and according to Bryman and Bell (2003), a sample of 30\% of the population is adequate representation of the population to make inferences. The sample used in this study was therefore larger than the $30 \%$ thus enough to make inferences for the organisation.

Data collection: Sixty-two questionnaires (both hard and soft copies) were distributed (during the beginning of 2010) to randomly selected respondents in the seven programme units and head office of the nongovernmental organisation. These were returned via designated collection points and also by email. All questionnaires were pre-numbered and had a code for the programme unit to facilitate tracking. Out of the sixty-two questionnaires distributed for both top management and general employees, twenty-four were returned completed, an overall response rate of $39 \%$ which was quite encouraging. Seven questionnaires were for top management and out the seven, five were completed (71\%) and returned and out of the fifty-five questionnaires for general employees, 19 were completed (35\%) and returned. The apparently low response rate was due to lot of workshops taking place both inside and outside the country. Thus a good number of questionnaires were returned late and could not be considered. In addition to the survey the research made use of internal documents such as the NGO's Terms and Conditions of Service, strategic plans, draft HIV and AIDS workplace policy, memoranda, to get a deeper understanding of the issues probed. However documents considered classified and confidential such as budgets and financial statements could not be accessed.

\section{Results}

All the top managers said they met with their staff to plan about the organisation long-term objectives and strategies once or more every year and the plans stretched for five years. This fact was corroborated by $79 \%$ of the non managerial respondents. Establishment of this fact was essential in order to define their strategic postures. In this regard Wheelen and Hunger (2003) argued that strategy is the determination of the basic long term goals and activities of an organisation, and the adoption of courses of action and allocation of resources necessary for carrying out these goals. The finding suggests that the organisation conducts strategic planning involving all the levels of staff. Strategic planning is essential in that it spells the vision and how the organisation intends to get to their destination. It is within this stream or patterns of action that HIV/AIDS mainstreaming is either affected or ignored. All the top management respondents claimed that they sometimes included HIV and AIDS issues into the organisation plans. Where, when, and how often management did this could not be established. Minutes for the period 2003 to 2009 showed there was never an agenda item on HIV and AIDS. The result may imply lack of top management commitment as highlighted by UNAIDS, IATT (2008:16). A total of $68 \%$ of the employee respondents claimed HIV and AIDS issues are included into organisational plans. A total of $27 \%$ of the respondents said they are not included into the strategic plans while $5 \%$ of said they are sometimes included. On prioritising HIV and AIDS as strategic issues, $68 \%$ of the general employees said the organisation prioritised HIV and AIDS as strategic issues, $16 \%$ said the organisation did not and another $16 \%$ said sometimes it did. In view of the general employees, the NGO prioritised HIV and AIDS issues as strategic issues for the organisation, and this creates a fertile ground for mainstreaming HIV and AIDS.

A staggering $99 \%$ of the top managers confirmed that their organisation had experienced HIV and AIDS related problems at their workplaces. This attests to the finding by James, et al (2006) that NGOs are vulnerable to HIV and AIDS. Where $99 \%$ of the respondents identify the pandemic as a threat, through 
analyses of their situations it can be concluded that indeed the scourge has become a strategic issue in business. This result further underpins what Derna dis said about a strategic issue. He argued that an issue has a strategic implication if it has current or potential impact on an organisation performance or any phase of the strategic planning process, or has urgent consequences or impact or interdependence with other issues. Most top management were not aware of those who had been lost/laid off as a result of HIV and AIDS since 2003. Only $1 \%$ of top management claimed that the organisation had lost below 5 employees due to the pandemic. The Sphere Project (2004) suggests that risk/impact assessment is an important factor in identifying the susceptibility and vulnerability of an organisation to HIV and AIDS, an aspect which is thus missing in this NGO. Further to this all the sampled top managers could not translate the losses their organisation had incurred due to HIV and AIDS into monetary value. Even then none of the top management respondents considered the pandemic less important in their organisation. Fifty (50\%) of the responding top managers stated that they had clearly defined and communicated HIV and AIDS Policy frameworks at their workplaces. The other $50 \%$ said they did not have them in place. Whilst $58 \%$ of the non-managerial employees confirmed the organisation had a clearly defined and communicated policy on HIV and AIDS, $42 \%$ said the organisation did not have any policy in place. According to the Human Resources Policy at the NGO all staff who join the organisation are given all the Human Resources-related documents which include the Code of Conduct, Terms and Conditions of Service, the HIV and AIDS Workplace Policy together with an acknowledgement letter which is signed by the employee acknowledging they have read and understood all the policy documents.

Forty percent $(40 \%)$ of the top managers were positive that they had HIV and AIDS programmes at the workplace and $60 \%$ said they did not have them. One common workplace programme is flexi- working hours. Twenty five percent (20\%) of the non-managerial respondents confirmed that the organisation allowed employees with HIV and AIDS to work on a flexible schedule enabling them to go for their medical appointments and the remaining $75 \%$ were not aware of such policy. Document review revealed that the NGO had no policy in black and white about flexible working hours hence the $25 \%$ who confirmed its existence could be as a result of their managers' attitude. Document analysis showed that the NGO only offered a 100\% medical aid cover with chronic add-on package which caters for pandemics such as HIV and AIDS, which is in line with DPLG (2007) recommendations. No other programmes are in place such as training of staff in the area of HIV and AIDS as peer educators or counsellors for purposes of helping the HIV and AIDS infected and affected. This is contrary to DPLG's (2007) recommendation that among other things employees have to be educated to increase their awareness of HIV and AIDS. All the top managers claimed that they shared with their employees in meetings, workshops and learning circles about the importance of the pandemic to the organisation, individuals and the community. This was confirmed by $36 \%$ of the general employees' respondents, a fact disputed by $64 \%$ of the remaining respondents. All the managerial respondents claimed that they were aware of the government's HIV/AIDS laws and regulations in as far as the workplace is concerned. This reinforces the observation by UNAIDS (2002) that the pandemic has brought with it a host of laws and regulations. The employee respondents were generally aware of the laws that protect employees who are HIV positive (74\%). Both top management and employee respondents were positive that the NGO neither did monitoring and evaluation of HIV and AIDS mainstreaming nor had tools in place for monitoring the same. It was also established that the organisation had Learning Circles, where staff meet two days in a month to discuss and learn about issues critical to their departments. Workshops are conducted on a regular business as well as meetings for senior managers.

\section{Conclusion, Discussion and Recommendations}

The findings of this study clearly indicate that although the NGO engages in strategic planning, it does not strategically plan for HIV and AIDS. The major challenges faced by NGO were mainly to do with senior management commitment and apparent lack of knowledge on the impacts of HIV/AIDS on their organisation. All the sampled top managers could not translate the losses their organisation had incurred due to HIV and AIDS into monetary value. Management were not informed of absenteeism, staff attrition, or other such factors occasioned by HIV/AIDS. However the attitude and ignorance of management can be explained by other factors such as a culture of silence and denial of HIV/AIDS. Culture is of the challenges cited by UNAIDS, IATT (2008:16). Individuals living with HIV/AIDS are at liberty not to disclose their status and often do not 
for fear of stigmatisation. Again, it could be because of the prevailing labour laws in Zimbabwe which prohibit discrimination of the HIV and AIDS infected against their right to employment, so laying off will not be an option unless the infected employee brings a letter from a medical practitioner that they should be retired early on the grounds of ill-health (Statutory Instrument 202 of 1998, Labour Relations (HIV and AIDS) Regulations, 1998 - revised in 2006). The majority of employees (64\%) claimed that managers did not share with them the importance of the pandemic, then one can conclude that the top management were not committed and there was a lack of effective leadership on HIV/AIDS (UNAIDS IATT, 2008). Top management commitment to internally mainstream HIV and AIDS can be demonstrated through being proactive in fostering the formulation of enabling policy environments at the workplace. The results showed that top managers do not prioritise HIV and AIDS issues as compared to the other strategic business issues faced by the organisation. One senior manager thought that the issues of HIV and AIDS are better left to be dealt with by human resources managers and their departments only and not by the entire top management. This is apparently another barrier where HIV/AIDS is assigned to a single person who already has other tasks and may not be able to devote sufficient time to the topic (UNAIDS IATT, 2008). It can be noted from the findings that the organisation human resources department lacked in terms of properly orienting new staff about the policies and procedures which relate to HIV and AIDS. This was evidenced by the divergent responses from both management and employees on issues contained in the human resources document package given to staff on recruitment. For example the HIV and AIDS workplace policy was given to all staff, but was apparently never read and understood by both management and employees. The documents are just shoved in drawers and never given the attention they deserve. Staffs were not aware of the policies as well as the benefits that accrue to them from the policies. Orientation is not intensive enough to leave all new staff conversant with the contents of the policies.

There is no policy on flexi time but $25 \%$ of the general staff respondents said it is there and $75 \%$ said it not in place. The result clearly showed that a few top managers were supportive of their staff when they needed time off to seek medical attention. The study has revealed that communication of policies was not effective. This was evident from the lack of consensus among all respondents on either the presence or absence of HIV and AIDS workplace policies nor their dissemination in the organisation. The planning and managing of communication was not adequate resulting in lack of awareness, support, involvement and commitment from employees in various levels. According to the findings of this study, there was very little or no monitoring and evaluation of HIV and AIDS mainstreaming efforts. No surveys were carried out before planning and implementation of mainstreaming initiatives. Impact assessments were not done to measure the effectiveness of workplace policies, mapping out improvements for future HIV and AIDS mainstreaming efforts and to avoid making the same mistakes made in previous programmes. Only when organisations carryout business impact assessment can they be able to get the full strategic impact of the HIV and AIDS pandemic as argued by UNAIDS (June, 2000) (see also The Sphere, 2004). It has been shown that the ultimate HIV and AIDS business impact is experienced with declining reinvestments and declining productivity and reliability, factors which all lead to declining profitability. While management and staff were aware of the government laws and regulations on HIV/AIDS at the workplace this was not sufficient to propel them to internally mainstream HIV/AIDS. As part of its usual mandate the organisation was involved in HIV/AIDS mitigation activities which included helping the communities with drugs, food, viral load and CD4 count testing machines to hospitals, support to community Home Based Care initiatives, psychosocial support training, school fees and agricultural inputs. The organisation could not however use this comparative advantage to address the causes and effects of HIV/AIDS in an effective and sustained manner within their workplace.

In light of the foregoing discussion the study recommends several courses of action for the NGO in particular and others in similar circumstances. First and foremost there is need for openness on HIV and AIDS issues particularly at the top. A culture change may not always require financial outlays but require a change of heart and commitment on part of management. Management should take advantage of the many workshops and meetings to promote internal mainstreaming of HIV and AIDS. HIV and AIDS issues should be a permanent feature on the agenda of the organisation. Strength of NGOs is high literacy and level of education of staff and this should be fully exploited in the fight against HIV and AIDS. It was also noted that the NGO in question had learning circles, which can be another forum to educate and increase employee's awareness on HIV and AIDS. The same assistance the NGO was affording to the communities as part of its mandate could be 
extended to employees at insignificant cost. For example the employees can have their viral loads CD4 counts down within the organisation. Although ART is covered by the organisation's medical insurance drugs can still be availed to staff. Knowledge is a vital resource in mainstreaming HIV/AIDS. Again the implementation of the HIV and AIDS interventions can be effected based on sound legal foundations as provided by the statutes on the subject matter. (Statutory Instrument 202 of 1998, Labour Relations (HIV and AIDS) Regulations, 1998). The Instrument covers the prevention and management of HIV and AIDS in the workplace and is meant to ensure non-discrimination of HIV-infected employees and establishes the rights and responsibilities of both employers and employees. This is important because compliance with laws on the pandemic is central to mainstreaming of HIV and AIDS issues.

Without credible financial figures no company can determine the full strategic implication of the pandemic to its operations and future continuity (The Sphere, 2004). Thus impact assessments are encouraged in the organisation. Most NGOs involved in HIV and AIDS programmes have monitoring and evaluation tools to assess programme effectiveness. The same tools and methods can be adapted for internal use to do impact assessment of HIV and AIDS to the organisation. It is clear that the NGO's major weakness has been its inability to make use of its comparative advantages to internally mainstream HIV and AIDS. A more structured and coordinated response to internal mainstreaming is necessary. Senior management has to be sensitised on the importance of HIV and AIDS mainstreaming. There after the organisation should follow the steps as recommended in various mainstreaming toolkits such as the 'ZGF HIV and AIDS mainstreaming toolkit' (2011). Mainstreaming for the NGO given its comparative advantage simply means modifying what they are already doing to make it more relevant to HIV and AIDS (ZGF, 2011). As an example the learning circles can be structured such that HIV and AIDS becomes a mandatory topic, staff induction programmes can emphasize HIV and AIDS policy of the organisation. Whatever could have been going on in the organisation in terms of HIV/AIDS internal mainstreaming was informal and uncoordinated for example some managers allowed infected and affected employees to work flexi time outside the policy of the organisation. The study only provided a snapshot on internal mainstreaming in one NGO operating in Zimbabwe. More detailed studies are required involving more NGOS, especially targeting local ones whose operations are restricted to Zimbabwe.

\section{References}

Baker, S., Pramualratana, A., Sartsara, S., Rumakom, P., Guest P., Schenek, K. Suksakulwat S., Panakitsuwan, S. \& Moonmeung, S. (2004). Using Incentives to Encourage AIDS Programs and Policies in the Workplace: A study of Feasibility \& Impact in Thailand, Horizons, Population Inc.

Barret, D. (2003). Corporate Partnerships to Combat HIV/AIDS, Harvard Business School

Bate, S. P. \& Robert, L. (2002). Knowledge Management and Communities of Practice in the Private Sector: Lessons from Modernising the National Health Service in England \& Wales, Public Administration, UK

Bryman, A. \& Emma, B. (2003). Business Research Methods, Oxford University Press

Chibukire, N. (2007). Why Mainstream HIV and AIDS in the World of Work. Community Development Resource Association (CDRA). 2004. Positive Organisation: Living and working with the invisible impact of HIV/AIDS

Department of Provincial Local Government (DPLG). (2007). Framework for an Integrated Local Government Response to HIV and AIDS

Dern- dis. (2003). http://www.las-cruces.org

Holden, S. (2003). HIV/AIDS Mainstreaming. A definition, some experiences and strategies

Halogen (HIV/AIDS and Local Government Learning Network). (2009). Municipal Brief1, Mainstreaming HIV/AIDS into Municipal IDPs

James, R. and Katundu, B. (2006). Counting the Organisational Cost of HIV/AIDS to Civil Society Organisations- Pilot Research Study, Malawi, International NGO Training and Centre (INTRAC).

ING Barings Bank. (2004). The Economic Impact of AIDS in South Africa

International Labour Organisation (ILO). (2006). HIV/AIDS and work: Global Estimates.

Koster, W. \& Neema, S. (2009). Implementation and effects of HIV and AIDS in the Workplace policies in Ugandan non-governmental organizations involved in the STOP AIDS NOW! Project 'Managing HIV/AIDS in the workplace. 
Mauambeta, D. C. (2008). HIV/AIDS Mainstreaming in Conservation. The Case of WESM Blantyre

Ministry of Health and Child Welfare. (2009). Zimbabwe National HIV Estimates 2009

Mullins, D. (2002). Mainstreaming HIV and AIDS into Development: What it can look like. OXFAM GB. www.oxfam.org.uk

Pennap, G. R. I., Chaanda, M. \& Ezirike, L. (2011). A Review of the Impact of HIV/AIDS on Education, the Workforce and Workplace: The African Experience. The Social Science, 6(2), 164-168

Swiss Agency for Development and Cooperation. (2004). Mainstreaming HIV/AIDS in Practice

SAfAIDS \& HIVOS. (2007). Managing HIV and AIDS in the World of Work: Experiences from Southern Africa

UK Consortium on AIDS and Development. (2004). Working positively: A guide for NGOs managing HIV/AIDS in the workplace.

UNAIDS \& GTZ. (2002) Mainstreaming HIV AND AIDS: A Conceptual Framework and Implementing Principles, Accra: UNAIDS \& GTZ. http://www.afronets.org/files/mainstream.pdf

UNAIDS. (2004). Support to Mainstreaming AIDS in Development', UNAID Secretariat Strategy Note and Action Framework 2004-2005. Retrieved from http://data.unaids.org/UNAdocs/mainstreaming_strategynote_enpdf (Accessed 11 July 2012)

UNAIDS. (2004). Report on the Global AIDS Epidemic

UNAIDS. (2005). Effectiveness of Multilateral Action Against AIDS

UNAIDS. (2010). Report on Global AIDS Epidemic: Global Report

UNAIDS IATT (UNAIDS Inter---Agency Task Team on Education). (2008). Toolkit for Mainstreaming HIV and AIDS in the Education Sector: Guidelines for Development Cooperation Agencies, Paris: UNESCO. http://unesdoc.unesco.org/images/0015/001566/156673e.pdf

UNDP. (1999). Mainstreaming the Policy and Programming Response to the HIV Epidemic. Issue Paper No.33

UNAIDS/GTZ. (2002). Mainstreaming HIV/AIDS

UNDP Bureau for Development. (2004). Supporting National HIV and AIDS Responses: An Implementation Approach.

VSO (Voluntary Service Overseas). (2004). HIV and AIDS Mainstreaming Guide for VSO Offices, London: VSO. http://www.vso.org.uk/Images/hiv---and---aids---mainstreaming---guidetcm79---23209.pdf

Wheelen, T. \& Hunger, D. (2003). Strategic Management and Business Policy. http://www.socialresearchmethods.net

Zambian Governance Foundation. (2011). HIV and AIDS mainstreaming toolkit for civil society organisations in Zambia

Zimbabwe Statutory Instrument 202 (1998). Labour Relations (HIV \& AIDS Regulations, 1998, revised 2006) 